\title{
Currency Substitution and Monetary Policy Effects: The Case of Latin American Countries
}

\author{
Hisao Kumamoto $^{1}$ \& Masao Kumamoto ${ }^{2}$ \\ ${ }^{1}$ Faculty of Economics, Dokkyo University, Saitama, Japan \\ ${ }^{2}$ Faculty of Economics, Tokyo Keizai University, Tokyo, Japan \\ Correspondence: Hisao Kumamoto, Faculty of Economics, Dokkyo University, 1-1, Gakuen-cho, Soka-shi, \\ Saitama 340-0042, Japan. Tel: 81-48-942-8142. E-mail: kumamoto@dokkyo.ac.jp
}

Received: December 4, 2016

Accepted: December 31, 2016

Online Published: January 10, 2017

doi:10.5539/ijef.v9n2p32

URL: http://dx.doi.org/10.5539/ijef.v9n2p32

\begin{abstract}
In this study, we empirically investigate how currency substitution transmits foreign monetary policy shocks to domestic countries and evaluate how the central bank respond to real exchange rate movements in three inflation-targeting Latin American countries under currency substitution, namely Chile, Mexico and Peru, between 2000 and 2011. Our model is based on a small open economy dynamic stochastic general equilibrium model that incorporates currency substitution and incomplete financial markets, and we estimate it by using Bayesian estimation techniques. Our empirical results are as follows. First, the degree of currency substitution is higher in Mexico, while it is negligible in Chile and Peru, which reflects the slight differences in the parameter values capturing the preference for the domestic currency among these countries. Second, the estimated coefficients of the real exchange rate gap in the monetary policy rule are high, meaning that the central banks in these countries actively respond to real exchange rate movements to diminish real exchange rate volatility. Third, domestic monetary policy influences the domestic economy through the real interest rate channel. On the contrary, foreign monetary policy has a significant effect in Mexico, while it is insignificant in Chile and Peru. This finding suggests the potential instability of currency substitution in that slight changes in the parameter values capturing the preference for the domestic currency alter the degree of insulation from foreign monetary policy shocks.
\end{abstract}

Keywords: Bayesian estimation, currency substitution, dynamic stochastic general equilibrium model, Latin America

\section{Introduction}

Currency substitution (CS), namely when domestic residents use foreign currency in their economic transactions, can be observed in many developing and transition countries that have suffered high inflation. In conditions of high inflation, the public starts to use foreign currency such as the U.S. dollar, because high inflation decreases the purchasing power of the domestic currency. Many theoretical and empirical studies of CS examine its effects on monetary policy through two channels.

First, a high degree of CS makes the nominal interest rate react strongly to even small changes in monetary policy, leading to higher exchange rate volatility (e.g., Girton \& Roper, 1981; Isaac, 1989; Mahdavi \& Kazemi, 1996).

Among empirical analyses, Akçay et al. (1997) used an E-GARCH model and found that the degree of CS has significant effects on Turkish lira/U.S. dollar exchange rate volatility. Yinusa (2008) estimated exchange rate volatility in Nigeria by using a GARCH model and found that both the degree of CS and exchange rate volatility have a bidirectional causality. The second channel through which CS restricts the ability of monetary policy is insulation from foreign shocks. For example, Rogers (1990) showed that the functioning of the flexible exchange rate system that could insulate from foreign price shocks may be lost in the presence of CS. Batini et al. (2008) and Felices and Tuesta (2013) constructed a dynamic stochastic general equilibrium (DSGE) model of CS, and showed that the marginal utility of consumption depends on the weighted average of domestic and foreign interest rates, where the weight represents the degree of CS. These features imply that as the degree of CS rises, the central bank's ability to stabilize the inflation rate and output by using the domestic nominal interest rate 
diminishes. These findings confirm the importance of central banks in developing countries considering the existence of CS when they formulate monetary policy.

Since the 1990s, inflation targeting has become a popular monetary policy instrument in not only advanced countries but also emerging economies. In Latin America, for example, it was introduced by Chile in 1990, by Mexico in 1998, and by Peru in 2002.

In general, central banks in inflation-targeting advanced countries argue that policy should respond to exchange rate movements only if they threaten the attainment of the inflation objective. However, some theoretical studies state that emerging countries can achieve stability by actively responding to exchange rate movements, since exchange rates in emerging countries tend to be volatile because of their shallow currency market and short history of stable inflation (e.g., Amato \& Gerlach, 2002; Aghion et al., 2009). In addition, as mentioned above, CS could be another source of exchange rate volatility. Indeed, the Central Bank of Peru's inflation-targeting framework takes explicit account of the risks stemming from financial dollarization, actively intervening in the foreign exchange market to smooth exchange rate fluctuations and build international reserves as a self-insurance mechanism against negative external shocks.

Against this background, this study investigates the extent to which CS transmits foreign monetary policy shocks to domestic countries and evaluates the central bank's response to real exchange rate movements. In particular, we focus on three inflation-targeting Latin American countries under CS: Chile, Mexico, and Peru.

Our study is related to research on monetary policy rule in inflation-targeting countries (e.g., Aizenman et al., 2011). However, we estimate, using Bayesian estimation techniques, a monetary policy rule based on a small open economy DSGE model incorporating CS and incomplete financial markets. (Note 1) Castillo et al. (2013) estimated, using Bayesian methods, a DSGE model incorporating CS in Peru. However, they considered a single country, making comparative analyses among countries impossible, while our sample comprises three countries. This extension allows a direct cross-country comparison.

While, our DSGE model is based on those presented by Batini et al. (2008) and Felices and Tuesta (2013), we extend their models to incorporate incomplete financial markets in which representative households cannot access complete sets of contingent bonds, since the complete financial market framework is considered to be unsuitable for emerging country studies. In particular, such a framework leads to unrealistic results on the risk-sharing and uncovered interest rate parity (UIP) conditions. The risk-sharing condition predicts a high cross-correlation between the real exchange rate and relative consumption, although, as Chari et al. (2002) found, the data do not show a clear pattern. Similarly, the UIP condition states that the expected change in the nominal exchange rate is proportional to the interest rate differential, although a large body of empirical evidence does not support this result. Lane and Milesi-Ferretti (2001) emphasized that net foreign assets play a significant role in determining the interest rate differential. By contrast, the UIP condition does not hold in the incomplete financial market framework, and the deviation from the uncovered interest rate condition is determined by net foreign assets. Thus, we follow Kumamoto and Kumamoto (2014), who introduced CS through the money-inthe-utility-function (MIUF) framework and assumed an incomplete financial market structure, to derive a tractable model in terms of the output gap, domestic inflation rate, and real exchange rate deviation from the natural level (hereafter, the real exchange rate gap).

The remainder of this paper is organized as follows. Section 2 reviews the historical background and practices of the three examined Latin American countries. We introduce the small open economy DSGE model in Section 3 and estimate it in Section 4, using Bayesian estimation methods. Section 5 concludes.

\section{Inflation Targeting in Latin America}

In this section, we review the historical background and practices of inflation targeting in Chile, Mexico, and Peru. (Note 2).

\subsection{Chile}

According to the Basic Constitutional Act (Section3), the objective of the Banco Central de Chile (BCC) is "to look after the stability of the currency and the normal functioning of the internal and external payments system".

The BCC has adopted an explicit inflation target since 1990, with the other above-mentioned objectives, including the sustainable current account deficit and exchange rate band, coupled with it until 1999. At the beginning, a narrow inflation target was specified based on CPI inflation rates. However, since 2000, the BCC has aimed to keep annual inflation within a target range of $2-4 \%$ and as close to $3 \%$ as possible. The launch of this framework was consistent with the shift from the exchange rate band to a flexible exchange rate regime in 1999. 
Interest rates have served as the primary monetary instrument since 1985. For example, it was the three-month real interest rate from 1985 to April 1995. In May 1995, this was changed to an overnight-real interest rate. The BCC has defined a target level for the interbank rate since August 2001.

\subsection{Mexico}

In December 1994, Mexico abandoned its fixed exchange rate system and allowed the Mexican peso to float against speculative market pressures during the balance-of-payments and currency crisis. The rapid depreciation of the Mexican peso led to fears of inflation. To stabilize inflation expectations, a new nominal monetary policy anchor was needed.

Since September 1995, the Banco de México (BM) has therefore set a target level for banks' cumulative current account balances that it holds. The implementation of such neutral monetary policy is called as the "zero-average reserve requirement" system. Within 28-day maintenance periods, each bank has to manage its current account balances so that its daily balances sum to zero at the end of each period. In other words, the system is designed for banks to avoid overdrafts or positive balances on their current accounts on average. The BM does not pay interest on positive balances, while it charges interest on overdrafts. Moreover, at the end of each period, the BM charges interest at twice the 28-day CETES2 rate on all negative accumulated balances. When the BM conducts contractionary monetary policy, it announces a negative balance target, called a corto. When this target is implemented, the BM provides all the liquidity needed by the financial system; however, the corto is provided at a penalty rate that is twice the overnight interbank rate. Its implementation has thus placed upward pressure on interbank interest rates.

In 1998, the BM adopted inflation targeting. For example, target inflation rates were set to no more than $13 \%$ in 1999 (for the next five years), $3 \%$ in 2001, and 3\% with a margin of tolerance of $\pm 1 \%$ in 2002. In 2003, the target level for banks' current account balances held at the BM changed from accumulated balances to daily balances. Once macroeconomic stability and financial deepening had been attained in 2003, the BM replaced the corto with overnight interbank rate as its operating target.

\subsection{Peru}

The Banco Central de Reserva del Perú (BCRP) implemented a monetary-targeting framework and used the annual monetary base growth rate as its intermediate target during the disinflation process from 1991 to 2001 . A monetary target is desirable for the hyperinflation environment, since it makes it easier to communicate the monetary policy stance and provides an indicator of commitment to disinflation. On the contrary, such a monetary target is less helpful in a low inflation environment because the relationship between the monetary aggregate and inflation rate becomes unstable. Thus, the operational target moved from monetary base to the interbank overnight interest rate when the inflation rate was low. In 2002, the BCRP adopted inflation targeting. The benchmark interest rate for standing facilities acts as a ceiling interbank interest rate, while the overnight deposits interest rate acts as the floor, forming the so-called "corridor".

Inflation targeting in Peru explicitly takes into account the risks caused by financial dollarization. Besides interest rates, several unconventional quantitative instruments have also been adopted in Peru. The BCRP aggressively intervenes in the foreign exchange market to stabilize exchange rate and it builds international reserves to tame the impact of capital flows. The BCRP has also set high reserve requirements on foreign currency liabilities to address liquidity and foreign currency credit risk.

\section{The Model}

\subsection{Basic Setup}

Our model is based on the two-country small open economy DSGE model proposed by Kumamoto and Kumamoto (2014). (Note 3) It is a standard New Keynesian model that has monopolistically competitive firms setting their prices in a staggered fashion. It also introduces CS through the MIUF and assumes an incomplete financial market structure.

The model assumes that society consists of the domestic and a foreign country. The world size is normalized to 1 , where a fraction $[0, n]$ lies in the domestic country, while $(n, 1]$ lies in the foreign country. A continuum of monopolistic competitive firms produce differentiated tradable goods. The domestic and the foreign country produce goods indexed by $j \in[0, n](\operatorname{good} H)$ and those indexed by $j \in(n, 1](\operatorname{good} F)$, respectively.

\subsubsection{Households}

Representative agent $h$ belonging to the domestic economy obtains positive utility from consumption and the real holdings of both the domestic currency (currency $H$ ) and the foreign currency (currency $F$ ) and negative utility 
from labor supply. Therefore, preference of the representative agent $h$ is represented by the following utility function:

$$
E_{0} \sum_{t=0}^{\infty} \beta^{t} U^{h}\left(C_{t}, \frac{M_{H, t}^{d}}{P_{t}}, \frac{S_{t} M_{F, t}^{d}}{P_{t}}, N_{t}^{s}\right)
$$

where

$$
\begin{gathered}
U^{h}\left(C_{t}, M_{H, t}{ }^{d} / P_{t}, S_{t} M_{F, t}{ }^{d} / P_{t}, N_{t}^{s}\right)=\left(X_{t}^{l-\sigma} / 1-\sigma\right)-\left(N_{t}^{s, l+\varphi} / 1+\varphi\right) \\
X_{t}=\left[\omega C_{t}^{(\theta-1) / \theta}+(1-\omega) Z_{t}^{(\theta-1) / \theta}\right]^{\theta /(\theta-1)}, Z_{t}=\left[\gamma\left(M_{H, t}{ }^{d} / P_{t}\right)^{(v-1) / v}+(1-\gamma)\left(S_{t} M_{F, t}{ }^{d} / P_{t}\right)^{(\nu-1) / v}\right]^{v /(v-1)}
\end{gathered}
$$

$M_{H, t}{ }^{d}$ and $M_{F, t}{ }^{d}$ are the nominal holdings of currencies $H$ and $F, P_{t}$ is the consumer price index, $S_{t}$ is the nominal exchange rate (in terms of the domestic currency per unit of the foreign currency). $N_{t}^{s}$ is labor supply. $X_{t}$ and $Z_{t}$ are the consumption-currency index, and the currency index, respectively. In addition, $\beta$ is the intertemporal discount factor, and $\sigma$ and $\varphi>0$ represent the coefficient of risk aversion and the inverse elasticity of labor supply, respectively. $\omega$ is the weight of consumption in the consumption currency index, $\theta$ captures the degree of complementary or substitutability between consumption and the currency index, $\gamma$ is the preference for currency $H$ within the currency index, and $v$ represents the elasticity of substitution between currencies $H$ and $F . C_{t}$ is the consumption index:

$$
\begin{gathered}
C_{t}=\left[(1-\alpha)^{1 / \eta}\left(C_{H, t}\right)^{(\eta-1) / \eta}+\alpha^{1 / \eta}\left(C_{F, t}\right)^{(\eta-1) / \eta}\right]^{\eta /(\eta-1)} \\
C_{H, t}=\left[\left(\frac{1}{n}\right)^{\frac{1}{\varepsilon}} \int_{0}^{n} C_{H, t} j^{\frac{\varepsilon-1}{\varepsilon}} d j\right]^{\frac{\varepsilon}{\varepsilon-1}}, C_{F, t}=\left[\left(\frac{1}{1-n}\right)^{\frac{1}{\varepsilon}} \int_{n}^{1} C_{F, t} j^{\frac{\varepsilon-1}{\varepsilon}} d j\right]^{\frac{\varepsilon}{\varepsilon-1}}
\end{gathered}
$$

where $C_{H, t}$ and $C_{F, t}$ are the consumption sub-indices of goods $H$ and $F$, respectively. $0<\alpha<1$ represents the preference for goods $F$, and assumed to be a function of the relative size of the foreign economy and the degree of openness; that is, $\alpha=(1-n) a$. In addition, $\varepsilon>1$ is the elasticity of substitution across the consumption of good $j$ within the domestic economy, denoted by $C_{H, t}(j)$ and within the foreign economy, $C_{F, t}(j)$, respectively. $\eta>0$ is the elasticity of substitution between goods $H$ and $F$.

The intertemporal budget constraint of agent $h$ is given by:

$$
P_{t} C_{t}+M_{H, t}+S_{t} M_{F, t}+P_{B H, t} B_{H, t}+S_{t} P_{B F, t} B_{F, t}=W_{t} N_{t}^{s}+M_{H, t-l}+S_{t} M_{F, t-l}+B_{H, t-l}+S_{t} B_{F, t-l}+\Gamma_{H, t}+T_{H, t}
$$

where $W_{t}$ is the nominal wage, $\Gamma_{H, t}$ is the dividend from the ownership of firms, and $T_{H, t}$ is the exogenous nominal amount of lump-sum cash transfers. The consumer price index $P_{t}$ is defined as:

$$
\begin{gathered}
P_{t}=\left[(1-\alpha)\left(P_{H, t}\right)^{1-\eta}+\alpha\left(P_{F, t}\right)^{1-\eta}\right]^{1 /(1-\eta)} \\
P_{H, t}=\left[\left(\frac{1}{n}\right) \int_{0}^{n} P_{H, t} j^{1-\varepsilon} d j\right]^{\frac{1}{1-\varepsilon}}, \quad P_{F, t}=\left[\left(\frac{1}{1-n}\right) \int_{n}^{1} P_{F, t} j^{1-\varepsilon} d j\right]^{\frac{1}{1-\varepsilon}}
\end{gathered}
$$

where $P_{H, t}$ and $P_{F, t}$ denote the price level. $P_{H, t}(j)$ and $P_{F, t}(j)$ denote the prices of good $j$ in terms of currency $H$. Two risk-free, one-period nominal bonds (bond $H$ and $F$ ) pay one units of currencies $H$ and $F$, respectively. $B_{H, t}$ and $B_{F, t}$ are the holdings of bonds $H$ and $F$ and $P_{B H, t}$ and $P_{B F, t}$ their prices, respectively. We assume that agent $h$ can hold both bonds, while agent $f$ can hold only bond $F$. Furthermore, we assume that when agent $h$ holds bond $F$, a transaction cost is required as a risk premium. The prices of bond $H$ and $F$ are given by

$$
P_{B H, t}=1 /\left(1+i_{H, t}\right), P_{B F, t}=1 /\left(1+i_{F, t}\right)
$$

where $i_{H, t}$ and $i_{F, t}$ denote nominal interest rates of bond $H$ and $F$, which applies for agent $h$. On the other hand, when agent $f$ purchases bond $F$, the nominal interest rate denoted by $i_{F, t}{ }^{*}$ is applied,

$$
1+i_{F, t}=\left(1+i_{F, t}{ }^{*}\right) \Psi\left\{S_{t}\left(B_{F, t}+M_{F, t}\right) / P_{H} Y\right\}
$$

where

$$
\Psi\left\{S_{t}\left(B_{F, t}+M_{F, t}\right) / P_{H} Y\right\}=\exp \left[-\kappa\left\{S_{t}\left(B_{F, t}+\left(M_{F, t}-M_{F}\right)\right) / P_{H} Y\right\}\right]
$$

The specification in Equation (9) follows Selaive and Tuesta (2003), Malik (2005), and Benigno (2009). $\Psi(\cdot)$ captures the transaction cost that satisfies $\Psi(0)=1$ and $\Psi^{\prime}(\cdot)<0$. The variable without the time subscript denotes its steady-state value. $Y$ is the initial steady-state level of the aggregate output of good $H$. Equation (9) implies 
that the transaction cost depends on the ratio of net foreign assets to the initial steady-state level of nominal output, which is consistent with the findings of Lane and Milesi-Ferretti (2001). As a borrower (net foreign assets are negative), agent $h$ is charged a premium on the foreign interest rate, while as a lender (net foreign assets are positive), agent $h$ obtains a lower foreign interest rate than that of agent $f$. Agent $h$ takes this ratio as given.

As for the foreign economy, representative agent $f$ belonging to the foreign country obtains positive utility from consumption and the real holdings of currency $F$ and negative utility from labor supply. Thus, the agent maximizes the following expected value of a discounted stream of period utilities:

$$
E_{0} \sum_{t=0}^{\infty} \beta^{t} U^{f}\left(C_{t}^{*}, \frac{M_{F, t}^{* d}}{P_{t}^{*}}, N_{t}^{* S}\right)
$$

where

$$
U^{f}\left(C_{t}^{*}, M_{F, t}^{*}{ }^{*} / P_{t}^{*}, N_{t}^{* S}\right)=\left(C_{t}^{* 1-\sigma} / 1-\sigma\right)+\left\{\left(M_{F, t}^{*} d / P_{t}^{*}\right)^{1-\zeta} / 1-\zeta\right\}-\left(N_{t}^{* S, 1+\varphi} / 1+\varphi\right)
$$

$M_{F, t}{ }^{*} d$ is the nominal holdings of currency $F, P_{t}^{*}$ is the consumer price index, and $N_{t}{ }^{*}$ is the total hours of labor supply. We assume that the coefficient of risk aversion in the consumption currency index $X_{t}$ of agent $h$ is equal to the coefficient of risk aversion in the consumption index $C_{t}{ }^{*}$ of agent $f$ and set it to $\sigma . \zeta$ is the coefficient of risk aversion in the real holdings of currency $F$. $C_{t}^{*}$ is given by

$$
\begin{gathered}
C_{t}^{*}=\left[\left(1-\alpha^{*}\right)^{1 / n}\left(C_{H, t}^{*}\right)^{(\eta-1) / \eta}+\alpha^{* 1 / \eta}\left(C_{F, t}^{*}\right)^{(\eta-1) / \eta}\right]^{\eta /(\eta-1)} \\
C_{H, t}^{*}=\left[\left(\frac{1}{n}\right)^{\frac{1}{\varepsilon}} \int_{0}^{n} C_{H, t}^{*} j^{\frac{\varepsilon-1}{\varepsilon}} d j\right]^{\frac{\varepsilon}{\varepsilon-1}}, C_{F, t}^{*}=\left[\left(\frac{1}{1-n}\right)^{\frac{1}{\varepsilon}} \int_{n}^{1} C_{F, t}^{*} j^{\frac{\varepsilon-1}{\varepsilon}} d j\right]^{\frac{\varepsilon}{\varepsilon-1}}
\end{gathered}
$$

where $C_{H, t}{ }^{*}$ and $C_{F, t}{ }^{*}$ are the consumption sub-indices of goods $H$ and $F$ and we assume that $1-\alpha^{*}=n a . C_{H, t}{ }^{*}(j)$ and $C_{F, t}{ }^{*}(j)$ are the consumption of good $j$.

Agent $f$ faces the intertemporal budget constraint given by

$$
P_{t}^{*} C_{t}^{*}+M_{F, t}{ }^{*}+P_{B F, t}{ }^{*} B_{F, t}{ }^{*}=W_{t}^{*} N_{t}^{* S}+M_{F, t-1}{ }^{*}+B_{F, t-1}{ }^{*}+\Gamma_{F, t}{ }^{*}+T_{F, t}{ }^{*}
$$

The foreign consumer price index $P_{t}^{*}$ is defined as:

$$
\begin{gathered}
P_{t}^{*}=\left[(1-\alpha)\left(P_{H, t}{ }^{*}\right)^{1-\eta}+\alpha\left(P_{F, t}{ }^{*}\right)^{1-\eta}\right]^{1-\eta} \\
P_{H, t}^{*}=\left[\left(\frac{1}{n}\right) \int_{0}^{n} P_{H, t}^{*} j^{1-\varepsilon} d j\right]^{\frac{1}{1-\varepsilon}}, P_{F, t}^{*}=\left[\left(\frac{1}{1-n}\right) \int_{n}^{1} P_{F, t}^{*} j^{1-\varepsilon} d j\right]^{\frac{1}{1-\varepsilon}}
\end{gathered}
$$

$P_{H, t}{ }^{*}$ and $P_{F, t}{ }^{*}$ denote the price level. $P_{H, t}{ }^{*}(j)$ and $P_{F, t}{ }^{*}(j)$ are the prices of good $j$ in terms of currency $F . P_{B F, t}{ }^{*}$ is the price of bond $F$, for which agent $f$ has applied:

$$
P_{B F, t}{ }^{*}=1 /\left(1+i_{F, t}{ }^{*}\right)
$$

Here, we define the terms of trade as

$$
\mathrm{T}_{t} \equiv P_{H, t} / P_{F, t}
$$

We assume the full pass-through of the exchange rate to the import price. Therefore, the law of one price holds:

$$
\begin{gathered}
P_{H, t}(j)=S_{t} P_{H, t}{ }^{*}(j), \quad P_{F, t}(j)=S_{t} P_{F, t}{ }^{*}(j) \\
P_{H, t}=S_{t} P_{H, t}{ }^{*}, \quad P_{F, t}=S_{t} P_{F, t}{ }^{*}
\end{gathered}
$$

We can express the real exchange rate as (Note 4)

$$
Q_{t}=S_{t} P_{t}^{*} / P_{t}=\left[1 /\left\{(1-a) \mathrm{T}_{t}^{1-\eta}+a\right\}\right]^{1 /(1-\eta)}, \text { as } n \rightarrow 0
$$

\subsubsection{Firms}

We assume a continuum of monopolistic competition firms, and firm $j$ produces a differentiated good $j \in[0, n]$ in the domestic country and good $j \in(n, 1]$ in the foreign country. All domestic firms use an identical constantreturns-to-scale technology:

$$
Y_{H, t}(j)=A_{t} N_{t}^{d}(j), \quad j=[0, n]
$$

$N_{t}^{d}(j)$ is the labor input. $A_{t}$ represents a common productivity shock for good $H$, and evolves as follows: 


$$
A_{t} / A=\left(A_{t-1} / A\right)^{\rho A} \exp \left[\varepsilon_{A, t}\right]
$$

$\rho_{A}$ is the autoregressive coefficient. $\varepsilon_{A, t}$ is a random variable and it is assumed to follow an identical and independent distribution with zero mean and constant variance, $\sigma_{\varepsilon A}{ }^{2}$.

The price setting decision is based on Calvo (1983) mechanism. Therefore, we assume that each firm faces an exogenous probability of changing prices given by $1-\chi$ in each period. Thus, with probability $\chi$, the firm cannot re-optimize the price represents the average price of all firms at previous period, $P_{H, t-1}$. From Equation (21) and the assumption that individual firms face the same demand function, they all choose the same price. We denote $P_{H, t}{ }^{+}$as optimal new price for a firm that sets its price at time $t$. Equation (6) evolves according to the following law of motion:

$$
P_{H, t}=\left[\chi P_{H, t-1}^{1-\eta}+(1-\chi) P_{H, t}^{+, 1-\eta}\right]^{1 /(1-\eta)}
$$

Where the market-clearing condition of goods is $j=[0, n]$ and a homogeneous production function is assumed, the firms' profit maximization problem can be written as:

$$
\max _{\left\{P_{t, t}^{P}\right\}} E_{t}\left[\sum_{k=0}^{\infty} \chi^{k} \Xi_{t, t+k}\left\{P_{H, t}^{+}\left(\frac{P_{H, t}^{+}}{P_{H, t+k}}\right)^{-\varepsilon}\left(\frac{P_{H, t+k}}{P_{t+k}}\right)^{-\eta}-P_{H, t+k} \Phi_{t+k}\left(\frac{P_{H, t}^{+}}{P_{H, t+k}}\right)^{-\varepsilon}\left(\frac{P_{H, t+k}}{P_{t+k}}\right)^{-\eta}\right\} \times(1-a) C_{t+k}+a C_{t+k}^{*} Q_{t+k}^{\eta}\right]
$$

$\Xi_{t, t+k} \equiv \beta^{k}\left(U_{C, t+k} / U_{C, t}\right)\left(P_{t} / P_{t+k}\right)$ is the stochastic discount factor and $\Phi_{t+k}$ is the real marginal cost.

As for the foreign economy, we assume that the prices are flexible for simplicity. All domestic firms in the foreign economy use an identical constant-returns-to-scale technology in the following form:

$$
Y_{F, t}(j)=A_{t}^{*} N_{t}^{* d}(j), \quad j \in(n, 1]
$$

where $N_{t}^{* d}(j)$ is the labor input. $A_{t}^{*}$ represents a common productivity shock for good $F$, and evolves as follows:

$$
A_{t}{ }^{*} / A^{*}=\left(A_{t-1}{ }^{*} / A^{*}\right)^{\rho A^{*}} \exp \left[\varepsilon_{A^{*}, t}\right]
$$

$\rho_{A^{*}}$ is the autoregressive coefficient. $\varepsilon_{A^{*}, t}$ is a random variable and it is assumed to follow an identical and independent distribution with zero mean and constant variance, $\sigma_{\varepsilon A^{*}}{ }^{2}$.

\subsubsection{Government}

We assume that the government's budget is balanced each period and that domestic government expenditure is zero. Therefore, the government's budget constraint can be written as

$$
T_{H, t}=M_{H, t}{ }^{S}-M_{H, t-1}{ }^{S}
$$

where $M_{H, t}^{S}$ denotes the nominal money supply of currency $H$ per capita. Equation (27) implies that the seigniorage revenues from domestic households are returned to them as lump-sum transfers.

As for the foreign government's budget, we assume that seigniorage obtained from foreign households is returned to them as lump sum transfers, while seigniorage obtained from domestic households is used to finance government expenditure. Furthermore, we assume that foreign government expenditure doesn't directly affect a foreign household's utility or the allocation of resources:

$$
\begin{aligned}
T_{F, t}{ }^{*} & =M_{F, t}{ }^{*}{ }_{s, F}-M_{F, t-1}{ }^{*}{ }_{s, F} \\
G_{t}{ }^{*} & =\left(M_{F, t}{ }^{s, H}-M_{F, t-l}{ }^{s, H}\right)
\end{aligned}
$$

where $M_{F, t}^{s, H}$ and $M_{F, t}{ }^{*}, F$ are the amounts of currency $F$ per capita circulated in the domestic and foreign countries, respectively. $G_{t}{ }^{*}$ is total foreign government expenditure (Note 5).

\subsubsection{Risk Sharing and UIP}

In incomplete financial markets, the risk-sharing condition holds in the expected first difference:

$$
\Psi\left\{S_{t}\left(B_{F, t}+M_{F, t}\right) / P_{H} Y\right\} E_{t}\left[\left(P_{t} / P_{t+1}\right)\left(S_{t+1} / S_{t}\right)\left(U_{C, t+1} / U_{C, t}\right)\right]=E_{t}\left[\left(P_{t}^{*} / P_{t+1}{ }^{*}\right)\left(U_{C^{*}, t+1} / U_{C^{*}, t}\right)\right]
$$

and the modified UIP condition is expressed as

$$
\left(1+i_{H, t}\right) /\left[\left(1+i_{F, t}{ }^{*}\right) \Psi\left\{S_{t}\left(B_{F, t}+M_{F, t}\right) / P_{H} Y\right\}\right]=E_{t}\left[\left(P_{t} / P_{t+1}\right)\left(S_{t+1} / S_{t}\right)\left(U_{C, t+1} / U_{C, t}\right)\right] / E_{t}\left[\left(P_{t} / P_{t+1}\right)\left(U_{C, t+1} / U_{C, t}\right)\right]
$$

\subsubsection{Monetary Policy Rule}

We assume that the monetary policy is implemented so that the central bank determines nominal interest rate responding to inflation, the output gap, and the real exchange rate as shown in the following equation:

$$
\begin{gathered}
\left(1+i_{H, t}\right) /\left(1+i_{H}\right)=\left\{\left(1+r_{t}^{n}\right) /\left(1+r^{n}\right)\right\}\left(\Pi_{H, l} / \Pi_{H}\right)^{\psi / \pi}\left(Y_{t} / Y_{t}^{n}\right)^{\psi y}\left(Q_{/} / Q_{t}^{n}\right)^{\psi \psi q} \exp \left[v_{t}\right] \\
v_{t}=\rho_{v} v_{t-l}+\varepsilon_{v, t}
\end{gathered}
$$


where $\Pi_{H, t}=P_{H, t} / P_{H, t-1}$ is the gross inflation rate of good $H . Y_{t}^{n}$ and $Q_{t}^{n}$ are the natural levels of output and the real exchange rate that prevail in a frictionless economy. (Note 6) Monetary policy shock $v_{t}$ follows an AR(1) process. $\varepsilon_{v, t}$ is a random variable and it is assumed to follow an identical and independent distribution with zero mean and constant variance, $\sigma_{v}{ }^{2} \cdot \psi_{q}$ represents the type of exchange rate regime. (Note 7).

For the foreign economy, since prices are flexible, we specify the monetary policy function according to the inflation-targeting rule, where the central bank determines nominal interest rate responding to the inflation gap:

$$
\begin{gathered}
\left(1+i_{F, t}{ }^{*}\right) /\left(1+i_{F}{ }^{*}\right)=\left(\Pi_{t}{ }^{*} / \Pi^{*}\right)^{\psi / \pi^{*}} \exp \left[v_{t}{ }^{*}\right] \\
v_{t}{ }^{*}=\rho_{v^{*}} v_{t-1}{ }^{*}+\varepsilon_{v^{*}, t}
\end{gathered}
$$

where $\Pi_{t}{ }^{*}=P_{t}{ }^{*} / P_{t-1}{ }^{*}$ is the gross inflation rate of good $F$. Monetary policy shock $v_{t}{ }^{*}$ follows an AR(1) process. $\varepsilon_{v^{*}, t}$ is a random variable and it is assumed to follow an identical and independent distribution with zero mean and constant variance, $\sigma_{v^{*}}^{2}$.

\subsection{Log-Linearized Model}

The log-linearized model around the initial symmetric steady state consists of the following 16 equations with 16 endogenous variables, $x_{t} \equiv\left\{y_{t}^{g}, y_{t}{ }^{*}, \pi_{t}, \pi_{H, t}, \pi^{*}, \Delta s_{t}, \hat{i}_{H, t}, \hat{i}_{F, t}, \hat{r}_{t}^{n}, v_{t}, v_{t}^{*}, a_{t}, a_{t}^{*}, q_{t}^{g}, n f a_{t}, \hat{i}_{F, t}^{*}\right\}$ and nine exogenous shocks, $\varepsilon_{t} \equiv\left\{\varepsilon_{y, t}, \varepsilon_{y^{*}, t}, \varepsilon_{A, t}, \varepsilon_{A^{*}, t}, \varepsilon_{\pi H, t}, \varepsilon_{u i p, t}, \varepsilon_{v, t}, \varepsilon_{v^{*}, t}, \varepsilon_{q, t}\right\}$. The lowercase letter denotes the percentage deviation from its steady-state value, except for the interest rate and net foreign assets. For the interest rate, $\hat{i}_{H, t}=i_{H, t}-i_{H}$, for example.

Domestic IS Curve:

$$
y_{t}^{g}=E_{t}\left[y_{t+1}^{g}\right]-\frac{\left(1+d_{1}\right)}{\sigma}\left(\hat{i}_{H, t}-E_{t}\left[\pi_{t+1}\right]-\hat{r}_{t}^{n}\right)+\frac{d_{2}(1-a)}{\sigma}\left\{(1-\delta) \Delta \hat{i}_{H, t+1}+\delta \Delta \hat{i}_{F, t+1}\right\}-\frac{\left(a+d_{1}\right) \kappa}{\sigma} n f a_{t}+\varepsilon_{y, t}
$$

where

$$
\begin{gathered}
d_{1}=a(2-a)(\eta \sigma-1), \quad d_{2}=\{(1 / \theta)-\sigma\}\left(1-d_{3}\right)\{\theta \beta /(1-\beta)\}, \quad d_{3}=\omega C^{\{(\theta-1) / \theta\}} /\left[\omega C^{\{(\theta-1) / \theta\}}+(1-\omega) Z^{\{(\theta-1) / \theta\}}\right] \\
\delta=\left(S M_{F} / P\right) /\left\{\left(M_{H} / P\right)+\left(S M_{F} / P\right)\right\}=\left[\left\{(\gamma /(1-\gamma))^{-\nu}\right\} /\left\{1+(\gamma /(1-\gamma))^{-\nu}\right\}\right]
\end{gathered}
$$

Natural Real Interest Rate:

$$
\hat{r}_{t}^{n}=\frac{\sigma \varphi d_{1}}{\varphi\left(1+d_{1}\right)+\sigma} E_{t}\left[\Delta y_{t+1}^{*}\right]-\frac{\sigma(1+\varphi)\left(1-\rho_{A}\right)}{\varphi\left(1+d_{1}\right)+\sigma} a_{t}
$$

Domestic Productivity:

$$
a_{t}=\rho_{A} a_{t-1}+\varepsilon_{A, t}
$$

New Keynesian Phillips Curve (NKPC):

$$
\pi_{H, t}=\lambda\left(\varphi+\frac{\sigma}{1-a}\right) y_{t}^{g}-\frac{\lambda\left(a+d_{1}\right)}{(1-a)^{2}} q_{t}^{g}+\lambda d_{2}\left\{(1-\delta) \hat{i}_{H, t}+\delta \hat{i}_{F, t}\right\}+\beta E_{t}\left[\pi_{H, t+1}\right]+\varepsilon_{\pi H, t}
$$

where $\lambda=(1-\chi)(1-\beta \chi) / \chi$.

Overall Inflation Rate:

Domestic Monetary Policy Rule:

$$
\pi_{t}=(1-a) \pi_{H, t}+a\left(\pi_{t}^{*}+\Delta s_{t}\right)
$$

$$
\begin{gathered}
\hat{i}_{H, t}=\hat{r}_{t}^{n}+\psi_{x} y_{t}^{g}+\psi_{\pi} \pi_{H, t}+\psi_{q} q_{t}^{g}+v_{t} \\
v_{t}=\rho_{v} v_{t-1}+\varepsilon_{v, t}
\end{gathered}
$$

Real Exchange Rate Gap:

$$
q_{t}^{g}=E_{t}\left[q_{t+1}^{g}\right]-\frac{\sigma(1-a)}{1+d_{1}} E_{t}\left[\Delta y_{t+1}^{g}\right]-\frac{(1-a)^{2} d_{2}}{1+d_{1}}\left\{(1-\delta) E_{t}\left[\Delta \hat{i}_{H, t+1}\right]+\delta E_{t}\left[\Delta \hat{i}_{F, t+1}\right]\right\}-\frac{\kappa(1-a)^{2}}{1+d_{1}} n f a_{t}+\varepsilon_{q, t}
$$

Modified Uncovered Interest Parity:

$$
\hat{i}_{H, t}=\hat{i}_{F, t}+E_{t}\left[\Delta s_{t+1}\right]+\varepsilon_{u i p, t}
$$


Risk Premium:

Net Foreign Assets:

$$
\hat{i}_{F, t}=\hat{i}_{F, t}^{*}-\kappa n f a_{t}
$$

$$
\beta n f a_{t}=n f a_{t-1}-\frac{a}{1-a} y_{t}^{g}+\frac{a}{1-a}\left\{\frac{(2-a) \eta}{1-a}-1\right\} q_{t}^{g}
$$

Foreign IS Curve:

$$
y_{t}^{*}=E_{t}\left[y_{t+1}^{*}\right]-\frac{1}{\sigma}\left(\hat{i}_{F, t}-E_{t}\left[\pi_{t+1}^{*}\right]\right)+\varepsilon_{y^{*}, t}
$$

Foreign AS Curve:

Foreign Productivity:

$$
y_{t}{ }^{*}=\{(1+\varphi) /(\varphi+\sigma)\} a_{t}^{*}
$$

Foreign Monetary Policy Rule:

$$
a_{t}^{*}=\rho_{A} * a_{t-1}{ }^{*}+\varepsilon_{A *, t}
$$

$$
\begin{gathered}
\hat{i}_{F, t}^{*}=\psi_{\pi^{*}} \pi_{t}^{*}+v_{t}^{*} \\
v_{t}{ }^{*}=\rho_{v^{*}} v_{t-l}{ }^{*}+\varepsilon_{v^{*}, t}
\end{gathered}
$$

$y_{t}{ }^{g} \equiv y_{t}-y_{t}{ }^{n}$ is the output gap, defined by the difference between actual output and an unobservable natural level of output in a frictionless economy. Similarly, $q_{t}^{g} \equiv q_{t}-q_{t}^{n}$ is the real exchange rate gap. $\pi_{t}$ and $\pi_{t}{ }^{*}$ are the overall inflation rates of the domestic and foreign countries, respectively. $r_{t}^{n}$ is the natural real interest rate. $n f a_{t}$ $\equiv S_{t}\left(B_{F, t}+M_{F, t}\right) / P_{H} Y$ represents net foreign assets relative to the initial steady-state level of nominal output. $\varepsilon_{v, t}$ and $\varepsilon_{v^{*}, t}$ are domestic and foreign demand shocks, respectively, $\varepsilon_{\pi H, t}$ is the cost-push shock, $\varepsilon_{u i p, t}$ is the UIP shock, and $\varepsilon_{q, t}$ is the real exchange rate shock.

Here, we discuss how domestic and foreign monetary policy influence the domestic economy $\left(y_{t}^{g}, \pi_{H, t}\right.$, and $\left.q_{t}^{g}\right)$ based on our model. Monetary policies are transmitted to the domestic economy through two main direct channels. The first is the real interest rate. We can see from Equation (36) that the higher $\hat{i}_{H, t}$, the higher real interest rate, which places downward pressure on $y_{t}^{g}$, downward pressure on $\pi_{H, t}$ through the NKPC (39), and appreciation pressure on $q_{t}^{g}$. (Note 8 ) The second channel is the marginal utility of the consumption channel. Note that the IS curve (36), NKPC (39), and real exchange rate gap (42) depend not only on the domestic but also on the foreign interest rate, which is an important feature of the CS model. As shown by Batini et al. (2008) and Felices and Tuesta (2013), the marginal utility of consumption can be written as:

$$
u_{c, t}=-\sigma c_{t}-d_{2}\left\{(1-\delta) \hat{i}_{H, t}+\delta \hat{i}_{F, t}\right\}
$$

We note that the higher the degree of CS, that is, higher $\delta$, the lower is the effect of domestic interest rate $\hat{i}_{H, t}$ and the greater is the effect of foreign interest rate $\hat{i}_{F, t}$ over the marginal utility of consumption $u_{c, t}$. The change in the marginal utility of consumption $u_{c, t}$ affects the IS curve through the Euler equation, the NKPC through the real marginal cost (since $u_{c, t}$ affects real wages through the intratemporal optimality condition), and the real exchange rate gap through the risk-sharing condition. Moreover, the effect through this channel on $u_{c, t}$ depends on $\sigma$ and $1 / \theta$. In other words, it depends on whether consumption and the currency index are complements $(1 / \theta>\sigma)$ or substitutes $(1 / \theta<\sigma)$. If $1 / \theta>\sigma$, a rise in $\hat{i}_{H, t}$ decreases $u_{c, t}$, which leads to a fall in $y_{t}^{g}$, a rise in $\pi_{H, t}$ and the depreciation of $q_{t}^{g}$, while the opposite holds if $1 / \theta<\sigma$. Foreign monetary policy is transmitted to the domestic economy through the marginal utility of the consumption channel. The direction of the effect is similar to domestic monetary policy: the higher $\delta$, the greater is the effect of foreign monetary policy on the domestic economy.

\section{Estimation}

\subsection{Data and Priors}

Since our model includes nine shocks or measurement errors, we can choose the following nine observable variables: $z_{t}=\left\{y_{t}^{g}, y^{*}, \pi_{t}, \pi_{H, t}, \pi_{t}^{*}, q_{t}^{g}, \hat{i}_{H, t}, \hat{i}_{F, t}^{*}, n f a_{t}\right\}$.

The sample period is chosen to include the era of inflation targeting, namely 2000Q1 to 2011Q4. Quarterly data are used.

Data on output gap $y_{t}^{g}$ and the real exchange rate gap $q_{t}^{g}$ are calculated from the logged real GDP and the logged 
real exchange rate against the U.S. dollar, respectively, and they are demeaned and then detrended by using the Hodrick Prescott filter with a smoothing parameter of 1,600. Data on domestic inflation rate $\pi_{t}$ and the inflation rates of domestic goods $\pi_{H, t}$ are calculated from the consumer price index and the producer price index, respectively, and they are demeaned. Data on domestic interest rate $\hat{i}_{H, t}$ are calculated from the three-month interbank rate. Data on foreign interest rate $\hat{i}_{F, t}^{*}$ are calculated from the three-month interbank rate in the United States and demeaned. Data on foreign output $y^{*}$ are calculated from logged real GDP and demeaned. Data on foreign inflation rate $\pi_{t}{ }^{*}$ are calculated from the consumer price index in the United States. The above data are available from the Economist Intelligence Unit. Data on net foreign assets are obtained from the External Wealth of Nations Dataset, 1970-2011 (retrieved from http://www.philiplane.org/EWN.html). These series are interpolated to a quarterly series by using the Chow and Lin (1971) procedure. (Note 9).

Table 1 specifies the prior distributions. We use the beta distributions for parameters 0 to 1 . Gamma distributions are used for positive parameters, and inverse gamma distributions are used for the standard deviations of the shocks. Some parameters need to be fixed. In order to match an annualized interest rate in the steady state of about $4 \%$, we set the discount factor to $\beta=0.99$. The share of foreign goods, $a$, is set to 0.4. (Note 10) We set the elasticity of substitution between goods $H$ and $F$ to $\eta=1.0$. Parameter measuring the degree of price stickiness, $\chi$, is assumed to 0.75 . (Note 11).

Table 1. Prior distributions

\begin{tabular}{|c|c|c|c|}
\hline Estimated parameters & Distribution & Mean & Std.dev. \\
\hline$\sigma$ & gamma & 1.0 & 0.1 \\
\hline$\varphi$ & gamma & 1.0 & 0.5 \\
\hline$\theta$ & gamma & 0.8 & 0.4 \\
\hline$\omega$ & beta & 0.8 & 0.1 \\
\hline$v$ & gamma & 2.0 & 1.0 \\
\hline$\gamma$ & beta & 0.6 & 0.1 \\
\hline$\kappa$ & beta & 0.001 & 0.0001 \\
\hline$\psi_{y}$ & gamma & 0.5 & 0.1 \\
\hline$\psi \pi$ & gamma & 1.8 & 0.3 \\
\hline$\psi \pi^{*}$ & gamma & 1.5 & 0.3 \\
\hline$\psi q$ & gamma & 0.5 & 0.1 \\
\hline$\rho_{v}$ & beta & 0.7 & 0.1 \\
\hline$\rho_{v^{*}}$ & beta & 0.7 & 0.1 \\
\hline$\rho_{A}$ & beta & 0.7 & 0.1 \\
\hline$\rho_{A^{*}}$ & beta & 0.7 & 0.1 \\
\hline$\sigma_{y}^{2}$ & inverse gamma & 0.1 & 0.009 \\
\hline$\sigma_{y *^{2}}$ & inverse gamma & 0.1 & 0.009 \\
\hline$\sigma_{\varepsilon A^{2}}$ & inverse gamma & 0.01 & 0.009 \\
\hline$\sigma_{\varepsilon A^{*^{2}}}$ & inverse gamma & 0.01 & 0.009 \\
\hline$\sigma_{\pi H^{2}}$ & inverse gamma & 0.01 & 0.009 \\
\hline$\sigma_{\text {uip }}^{2}$ & inverse gamma & 0.01 & 0.009 \\
\hline$\sigma v^{2}$ & inverse gamma & 0.01 & 0.009 \\
\hline$\sigma_{v^{*^{2}}}$ & inverse gamma & 0.01 & 0.009 \\
\hline$\sigma_{q^{2}}$ & inverse gamma & 0.01 & 0.009 \\
\hline \multicolumn{4}{|l|}{ Fixed parameters } \\
\hline$\beta$ & - & 0.99 & - \\
\hline$\eta$ & - & 1.0 & - \\
\hline$a$ & - & 0.4 & - \\
\hline$\chi$ & - & 0.75 & - \\
\hline
\end{tabular}

\subsection{Empirical Results}

Table 2 presents the Bayesian estimation results. First, we see that the weights attached to the foreign currency holdings in currency index $Z_{t}(1-\gamma)$ are 0.255 in Chile, 0.364 in Mexico, and 0.276 in Peru, which means that domestic residents obtain utility from the liquidity function of the foreign currency. The estimated elasticities of substitution between currencies $H$ and $F(v)$ are higher in Chile (3.533) and Peru (3.367), while lower in Mexico (1.895). Combining these results means that the point estimations of the steady-state value of CS $\delta$ are 0.022 for Chile, 0.258 for Mexico, and 0.038 for Peru. The value of $\delta$ also represents the extent to which foreign monetary policy affects the marginal utility of consumption, namely the degree of CS. Thus, we can expect that foreign monetary policy does have meaningful effects on the domestic economy in Mexico, while not in Chile and Peru. Note that in Mexico, although the elasticities of CS between currencies $H$ and $F(v)$ are lower, a small increase in 
$\gamma$ leads to a higher value of $\delta$, which restricts the degree of insulation from foreign monetary policy shocks.

As discussed in Section 3, the effects of domestic and foreign monetary policy on the marginal utility of consumption depend on the relative size of $\sigma$ and $1 / \theta$. From Table 2, we note that $1 / \theta=0.849>0.505=\sigma$ for Chile, $1 / \theta=1.238>0.512=\sigma$ for Mexico, and $1 / \theta=1.085>0.507=\sigma$ for Peru, which means that consumption and the currency index are complements in these countries. Thus, the marginal utility of the consumption channel leads to a fall in $y_{t}^{g}$, a rise in $\pi_{H, t}$, and the depreciation of $q_{t}^{g}$ following contractionary domestic and foreign monetary policy shocks.

As for the monetary policy rule, the coefficients of output gap $\psi_{y}$ are 0.381 for Chile, 0.500 for Mexico, and 0.285 for Peru. The coefficients of domestic inflation $\psi_{\pi}$ are 2.785 for Chile, 2.072 for Mexico, and 2.402 for Peru, satisfying Taylor's principle; however, these values are higher than those in previous studies. The coefficients of real exchange rate gap $\psi_{q}$ are 0.342 for Chile, 0.253 for Mexico, and 0.351 for Peru. These estimated values are also higher than those in previous studies. (Note 12) Thus, we can conclude that the central banks in these countries respond to real exchange rate movements actively.

Table 2. Parameter estimations

\begin{tabular}{|c|c|c|c|}
\hline & Chile & Mexico & Peru \\
\hline \multirow{2}{*}{$\sigma$} & 0.5048 & 0.5115 & 0.5074 \\
\hline & $(0.4888-0.5258)$ & $(0.4888-0.5391)$ & $(0.4888-0.5314)$ \\
\hline \multirow[b]{2}{*}{$\varphi$} & 5.2497 & 0.9205 & 1.2300 \\
\hline & (3.8221-6.6608) & $(0.4466-1.412) 1$ & $(0.5264-1.8820)$ \\
\hline \multirow{2}{*}{$\theta$} & 1.1773 & 0.8078 & 0.9220 \\
\hline & $(0.7810-1.5780)$ & $(0.1983-1.4637)$ & $(0.2274-1.8898)$ \\
\hline \multirow{2}{*}{$\omega$} & 0.7186 & 0.9315 & 0.9266 \\
\hline & $(0.5978-0.833)$ & $(0.8822-0.9781)$ & $(0.8499-0.9871)$ \\
\hline \multirow{2}{*}{$v$} & 3.5334 & 1.8945 & 3.3671 \\
\hline & $(1.9691-5.1175)$ & $(0.5990-3.1928)$ & $(1.5547-5.1377)$ \\
\hline \multirow{2}{*}{$\gamma$} & 0.7454 & 0.6359 & 0.7238 \\
\hline & $(0.6565-0.8313)$ & $(0.5223-0.7502)$ & $(0.6286-0.8524)$ \\
\hline \multirow{2}{*}{$\kappa$} & 0.0010 & 0.0010 & 0.0009 \\
\hline & $(0.0008-0.0012)$ & $(0.0008-0.0012)$ & $(0.0008-0.0011)$ \\
\hline \multirow[b]{2}{*}{$\psi_{y}$} & 0.3814 & 0.5003 & 0.2846 \\
\hline & $(0.2421-0.5026)$ & $(0.3509-0.6471)$ & $(0.1828-0.3812)$ \\
\hline \multirow[b]{2}{*}{$\psi_{\pi}$} & 2.7848 & 2.0724 & 2.4023 \\
\hline & $(2.3032-3.2385)$ & $(1.7021-2.4237)$ & (1.9709-2.8335) \\
\hline \multirow[b]{2}{*}{$\psi_{q}$} & 0.3417 & 0.2528 & 0.3512 \\
\hline & $(0.2208-0.4549)$ & $(0.1757-0.3313)$ & $(0.2339-0.4680)$ \\
\hline \multirow[b]{2}{*}{$\rho_{A}$} & 0.8382 & 0.7144 & 0.7066 \\
\hline & $(0.7425-0.9480)$ & $(0.5528-0.8765)$ & $(0.5557-0.8768)$ \\
\hline \multirow[b]{2}{*}{$\rho_{i H}$} & 0.4991 & 0.6417 & 0.6041 \\
\hline & $(0.4024-0.5945)$ & $(0.5548-0.7254)$ & $(0.4841-0.7221)$ \\
\hline \multirow{2}{*}{$\psi_{\pi^{*}}$} & 1.7204 & 1.6456 & 1.6246 \\
\hline & $(1.2749-2.1364)$ & $(1.2132-2.0681)$ & $(1.2149-2.0278)$ \\
\hline \multirow{2}{*}{$\rho_{A^{*}}$} & 0.9606 & 0.9592 & 0.9608 \\
\hline & $(0.9392-0.9825)$ & $(0.9361-0.9815)$ & $(0.9386-0.9821)$ \\
\hline \multirow[b]{2}{*}{$\rho_{i F^{*}}$} & 0.5216 & 0.5248 & 0.4893 \\
\hline & $(0.3813-0.6562)$ & $(0.3836-0.6665)$ & $(0.3469-0.6294)$ \\
\hline \multirow{2}{*}{$\sigma_{y}^{2}$} & 0.0876 & 0.0831 & 0.0852 \\
\hline & $(0.0767-0.0985)$ & $(0.0733-0.0922)$ & $(0.0753-0.0948)$ \\
\hline \multirow{2}{*}{$\sigma_{\pi H}^{2}$} & 0.0303 & 0.0071 & 0.0116 \\
\hline & $(0.0229-0.0380)$ & $(0.0053-0.0087)$ & (0.0086-0.0143) \\
\hline \multirow{2}{*}{$\sigma_{u i p}^{2}$} & 0.0457 & 0.0227 & 0.0165 \\
\hline & $(0.0385-0.0536)$ & $(0.0190-0.0263)$ & $(0.0138-0.0190)$ \\
\hline \multirow{2}{*}{$\sigma_{q}^{2}$} & 0.0718 & 0.0541 & 0.0376 \\
\hline & $(0.0577-0.0855)$ & $(0.0447-0.0630)$ & $(0.0309-0.0448)$ \\
\hline \multirow{2}{*}{$\sigma_{A}^{2}$} & 0.0868 & 0.0094 & 0.0093 \\
\hline & $(0.0524-0.1232)$ & $(0.0033-0.0162)$ & $(0.0034-0.0150)$ \\
\hline \multirow{2}{*}{$\sigma_{i H}^{2}$} & 0.0791 & 0.0233 & 0.0318 \\
\hline & $(0.0613-0.0976)$ & $(0.0174-0.0289)$ & $(0.0236-0.0401)$ \\
\hline 2 & 0.0760 & 0.0762 & 0.0758 \\
\hline$\sigma_{y^{*}}{ }^{2}$ & $(0.0681-0.0843)$ & $(0.0680-0.0846)$ & $(0.0676-0.0839)$ \\
\hline 2 & 0.0082 & 0.0067 & 0.0069 \\
\hline$\sigma_{A^{*}}{ }^{2}$ & $(0.0067-0.0096)$ & $(0.0053-0.0080)$ & $(0.0056-0.0082)$ \\
\hline 2 & 0.0117 & 0.0113 & 0.0104 \\
\hline$\sigma_{i F^{*}}$ & $(0.0083-0.0149)$ & $(0.0081-0.0145)$ & $(0.0074-0.0133)$ \\
\hline $1-\gamma$ & 0.2546 & 0.3641 & 0.2762 \\
\hline $1 / \theta$ & 0.8494 & 1.2379 & 1.0846 \\
\hline$\delta$ & 0.0220 & 0.2580 & 0.0375 \\
\hline
\end{tabular}

Note. The $90 \%$ probability interval is shown in parentheses. 
Chile

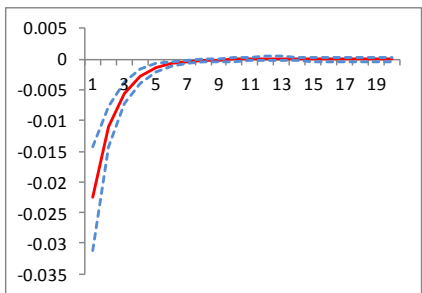

Chile

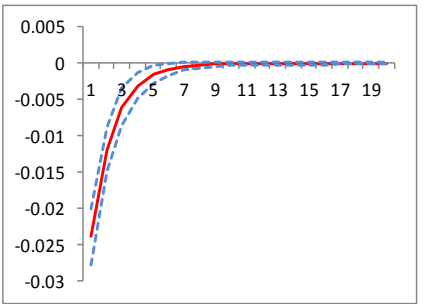

Chile

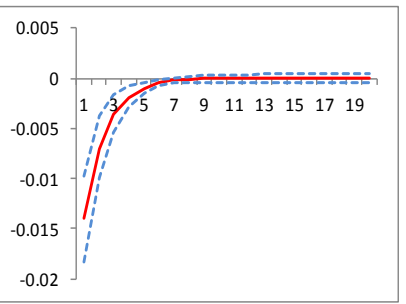

Mexico

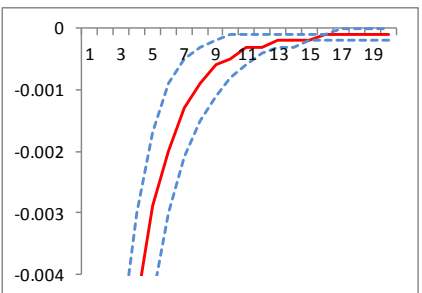

(a) Impulse Responses of $y_{t}^{g}$

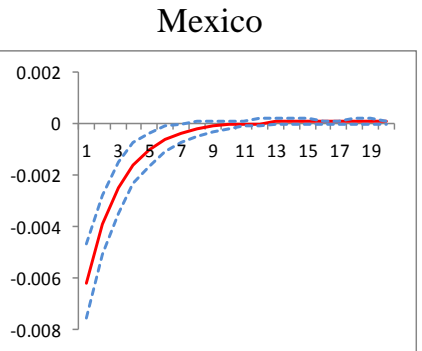

(b) Impulse Responses of $\pi_{H}$

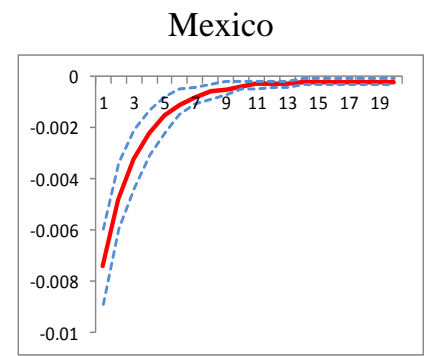

(c) Impulse Responses of $q_{t}^{g}$
Peru

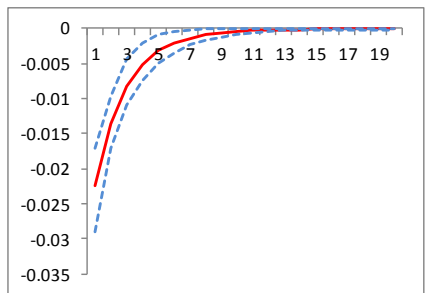

Peru

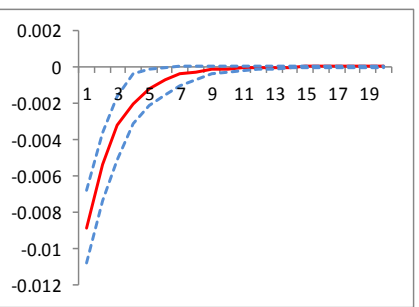

Peru

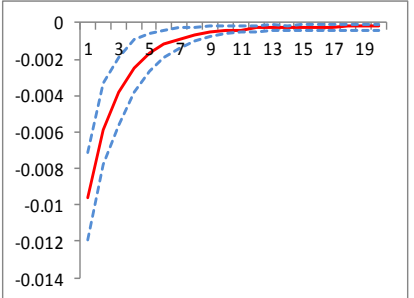

Figure 1. Impulse response functions: domestic monetary policy shock

Figures 1 and 2 show the impulse responses of $y_{t}^{g}, \pi_{H, t}$, and $q_{t}^{g}$ to domestic and foreign monetary policy shocks, respectively. For domestic monetary policy, we note that $y_{t}^{g}$ and $\pi_{H, t}$ decrease and $q_{t}^{g}$ appreciates in all countries following a contractionary domestic monetary policy shock. These results show that the marginal utility of the consumption channel is dominated by the real interest rate channel.

For foreign monetary policy, $y_{t}^{g}$ and $\pi_{H, t}$ increase and $q_{t}^{g}$ appreciates following a foreign contractionary monetary policy shock, which seems to be inconsistent with the marginal rate of substitution channel in the case of $1 / \theta>\sigma$ (complement). This is because the downward pressure on $\pi_{t}^{*}$ overrides the direct effect of higher $v_{t}{ }^{*}$. Ultimately, the foreign interest rate declines in response to a rise in foreign monetary policy shock $v_{t}{ }^{*}$. From the confidence bands, the impulse responses are insignificant in Chile and Peru, while they are significant in Mexico $y_{t}^{g}$ and $q_{t}^{g}$, which is consistent with our expectations. As mentioned above, slight changes in the parameter values capturing the preference for the domestic currency $(\gamma$ and $v$ ) alter the degree of insulation from foreign monetary policy shocks.

Chile

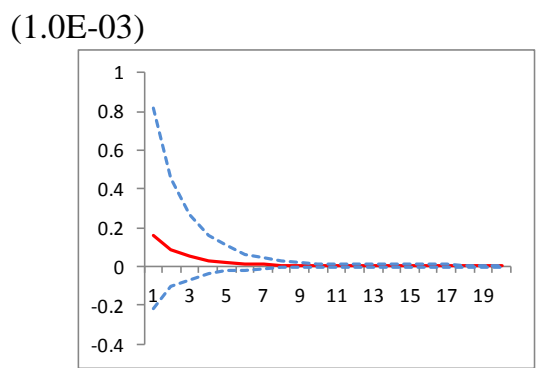

Mexico

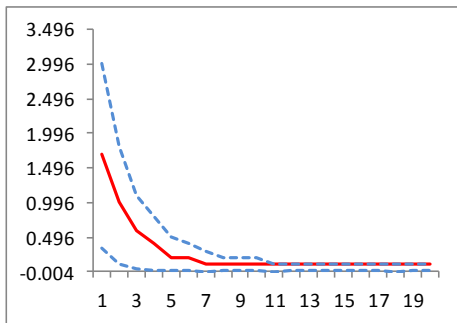

(a) Impulse Responses of $y_{t}^{g}$
Peru

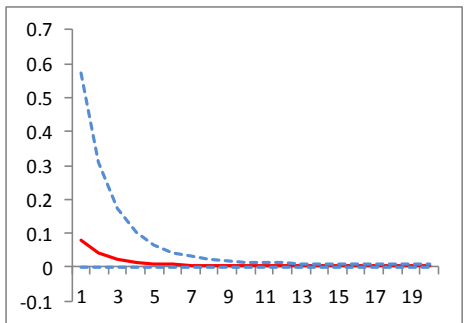


Chile

(1.0E-03)

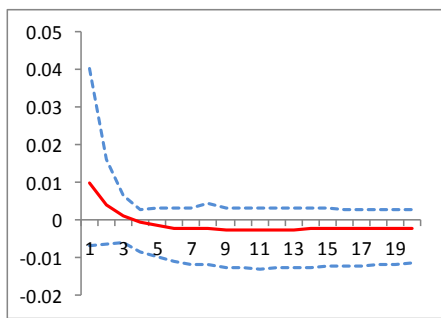

Chile

(1.0E-03)

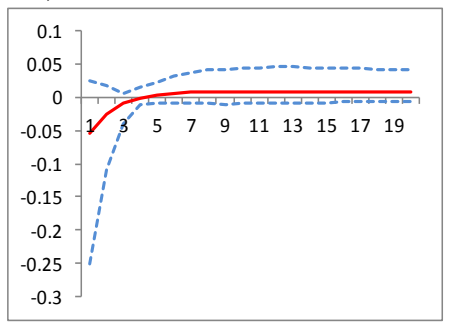

Mexico

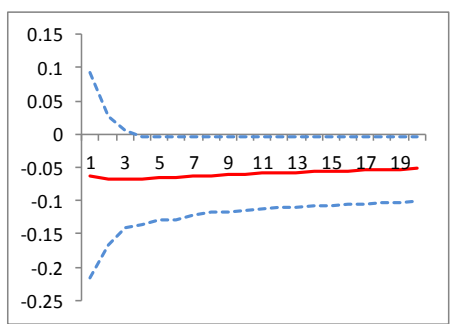

(b) Impulse Responses of $\pi_{H}$

Peru
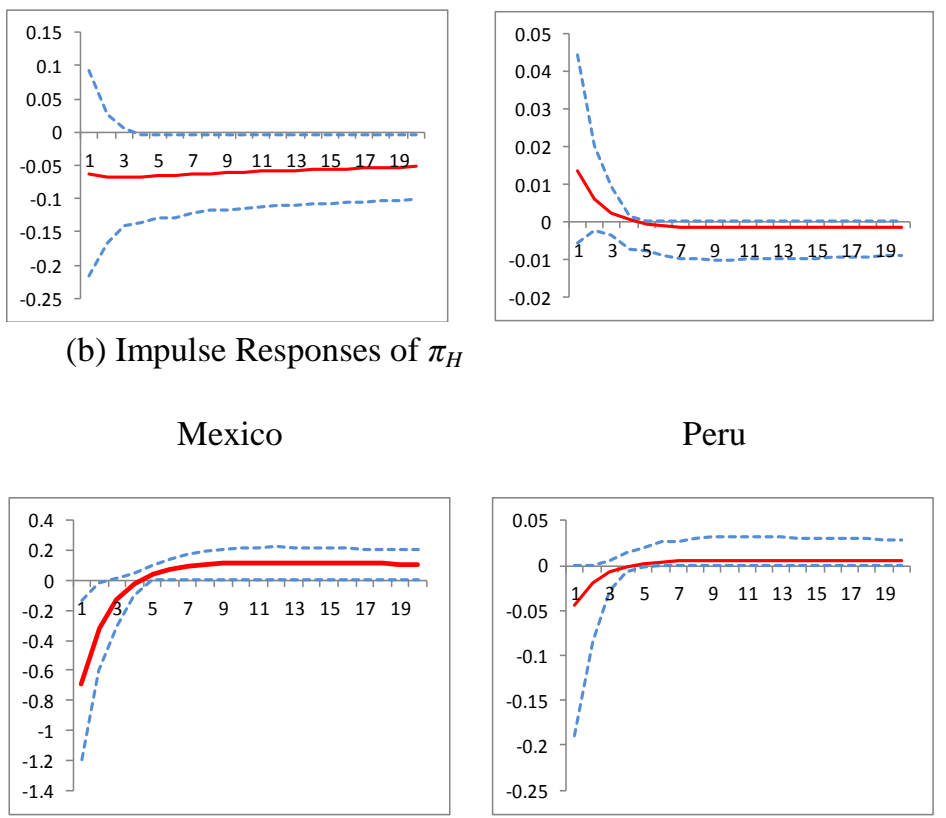

(c) Impulse Responses of $q_{t}^{g}$

Peru

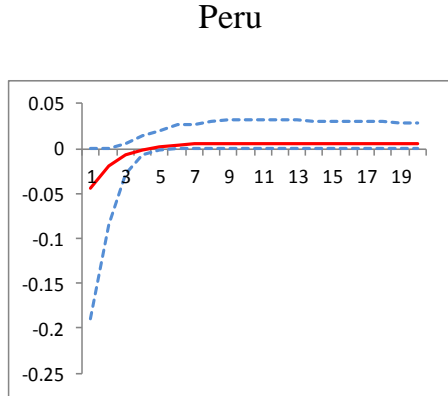

Figure 2. Impulse Response Functions: Foreign Monetary Policy Shock

\section{Conclusions}

In this study, we empirically evaluate the central bank's response to real exchange rate movements in three inflation-targeting Latin American countries that experience CS: Chile, Mexico, and Peru. We also examine the extent to which these exchange rate movements affect the domestic economy. Our model is based on the small open economy DSGE model developed by Kumamoto and Kumamoto (2014) that incorporates CS and incomplete financial markets, and we estimate it by using Bayesian estimation techniques.

Our empirical findings are as follows. First, the presented Bayesian estimation shows that domestic residents obtain utility from the liquidity function of foreign currency, consumption and the currency index are complements, and the degree of CS is higher in Mexico, while negligible in Chile and Peru, which reflects the slight differences in the parameter values capturing the preference for the domestic currency among these countries. Second, the estimated coefficients of the real exchange rate gap in the monetary policy rule are high, meaning that the central banks in these countries actively respond to real exchange rate movements to diminish the downsides of real exchange rate volatility. Lastly, domestic monetary policy has a significant impact on the domestic economy through the real interest rate channel. Foreign monetary policy has a significant effect in Mexico, while it is insignificant in Chile and Peru. This finding suggests the potential instability of CS in that slight changes in the parameter values capturing the preference for the domestic currency alter the degree of insulation from foreign monetary policy shocks.

Our findings show that if CS restricts the independence of domestic monetary policy, restrictions on foreign currency holdings would be useful to decrease their contribution to households.

\section{Acknowledgments}

The authors greatly acknowledge the helpful comments and suggestions to improve the quality of the paper received from the anonymous reviewers and the Associate Editor of this journal. This research was financially supported by a Grant-in-Aid for Scientific Research from the Japan Society for the Promotion of Science (C) no. 15K03536. The remaining errors are our own.

\section{References}

Aghion, P., Bacchetta, P., Ranciere, R., \& Rogoff, K. (2009). Exchange rate volatility and productivity growth: The role of financial development. Journal of Monetary Economics, 56(4), 494-513. http://dx.doi.org/10.1016/j.jmoneco.2009.03.015

Aizenman, J., Hutchison, M., \& Noy, I. (2011). Inflation targeting and real exchange rates in emerging markets. 
World Development, 39(5), 712-724. http://dx.doi.org/10.1016/j.worlddev.2010.11.005

Akçay, O. C., Alper, C. E., \& Karasulu, M. (1997). Currency substitution and exchange rate instability: The Turkish case. European Economic Review, 41(3-5), 827-835. http://dx.doi.org/10.1016/S0014-2921(97)00040-8

Amato, J. D., \& Gerlach, S. (2002). Inflation targeting in emerging market and transition economies: Lessons after a decade. European Economic Reviews, 46(4-5), 781-790. http://dx.doi.org/10.1016/S0014-2921(01)00213-6

An, S., \& Schorfheide, F. (2007). Bayesian analysis of DSGE models. Econometric Reviews, 26(2-4), 113-172. http://dx.doi.org/10.1080/07474930701220071

Batini, N., Levine, P., \& Pearlman, J. (2008). Optimal exchange rate stabilization in a dollarized economy with inflation targets. Banco Central de Reserva del Perú Working Paper Series, 2008-004. Retrieved from http://www.bcrp.gob.pe/docs/Publicaciones/Documentos-de-Trabajo/2008/Working-Paper-04-2008.pdf

Benigno, P. (2009). Price stability with imperfect financial integration. Journal of Money, Credit, and Banking, 4l(1), 121-149. http://dx.doi.org/10.1111/j.1538-4616.2008.00201.x

Calvo, G. A. (1983). Staggered prices in a utility maximizing framework. Journal of Monetary Economics, 12(3), 383-398. http://dx.doi.org/10.1016/0304-3932(83)90060-0

Castillo, P., Montoro, C., \& Tuesta, V. (2013). An estimated stochastic general equilibrium model with partial dollarization: A Bayesian approach. Open Economies Review, 24(2), 217-265. http://dx.doi.org/10.1007/s11079-012-9239-3

Chari, V. V., Kehoe, P. J., \& McGrattan, E. R. (2002). Can sticky price models generate volatile and persistent real exchange rates?. The Review of Economic Studies, 69(3), 533-563. http://dx.doi.org/doi.10.1111/1467-937X.00216

Chow, G. C., \& Lin, A. (1971). Best linear unbiased interpolation, distribution and extrapolation of time series by related series. Review of Economics and Statistics, 53(4), 372-375. Retrieved from http://links.jstor.org/sici?sici=0034-6535\%28197111\%2953\%3A4\%3C372\%3ABLUIDA\%E2.0.CO\%3B2-J

Felices, G., \& Tuesta, V. (2013). Monetary policy in a dual currency environment. Applied Economics, 45(34), 4739-4753. http://dx.doi.org/10.1080/00036846.2013.804165

Garcia, M., Garcia, P., \& Piedrauena, B. (2005). Fiscal and monetary policy rules: The recent Chilean experience, Central Bank of Chile, Working Paper, No. 340. Retrieved from http://citeseerx.ist.psu.edu/viewdoc/download?doi=10.1.1. 564.7327/pdf

Girton, L., \& Roper, D. (1981). Theory and implications of currency substitution. Journal of Money, Credit, and Banking, 13(1), 12-30. Retrieved from http://www.jstor.org/stable/1991805

Isaac, A. G. (1989). Exchange rate volatility and currency substitution. Journal of International Money and Finance, 8(2), 277-284. http://dx.doi.org/10.1016/0261-5606(89)90027-2

Kumamoto, M., \& Kumamoto, H. (2014). Currency substitution and monetary policy under the incomplete financial market. Japanese Journal of Monetary and Financial Economics, 2(2), 16-45. Retrieved from http://www. jsmeweb.org/jjmfe/pdf/2014aug/jjmfe_2014august_2.pdf

Lane, P., \& Milesi-Ferretti, G. M. (2001). Long-term capital movement. In B. S. Bernanke, \& K. Rogoff (Eds.), NBER macroeconomics annual 2001 (pp. 73-116). Cambridge: MIT Press.

Mahdavi, M., \& Kazemi, H. B. (1996). Indeterminacy and volatility of exchange rates under imperfect currency substitution. Economic Inquiry, 34(1), 168-181. http://dx.doi.org/10.1111/j.1465-7295.1996.tb01370.x

Malik, H. (2005). Monetary-exchange rate policy and current account dynamics. MPRA (Munich Personal RePEc Archive) Paper, No. 455. Retrieved from https://mpra.ub.uni-muenchen.de/455/1/MPRA_paper_455.pdf

Rogers, J. H. (1990). Foreign inflation transmission under flexible exchange rates and currency substitution. Journal of Money, Credit, and Banking, 22(2), 195-208. Retrieved from http://www.jstor.org/stable/1992307

Selaive, J. D., \& Tuesta, V. (2003). Net foreign assets and imperfect pass-through: The consumption real exchange rate anomaly. Central Bank of Chile Working Papers, No. 252. Retrieved from https://www.federalreserve.gov/ pubs/ifdp/2003/764/ifdp764.pdf

Sims, C. A. (2002). Solving linear rational expectations models. Computational Economics, 20(1), 1-20. 
http://dx.doi.org/10.1023/A:1020517101123

Torres, A. (2003). Monetary policy and interest rates: Evidence from Mexico. North American Journal of Economics and Finance 14(3), 357-379. http://dx.doi.org/10.1016/j.najef.2003.08.001

Yinusa, D. O. (2008). Between dollarization and exchange rate volatility: Nigeria's portfolio diversification option. Journal of Policy Modeling, 30(5), 811-826. http://dx.doi.org/10.1016/j.jpolmod. 2007.09.007

\section{Notes}

Note 1. See An and Schorfheide (2007) for a review of Bayesian methods for the estimation of DSGE models.

Note 2. See Garcia et al. (2005) for the monetary policy framework in Chile, Torres (2003) for Mexico, and Armas et al. (2014) for Peru.

Note 3. See Kumamoto and Kumamoto (2014) for details of the model.

Note 4. By using the above equations and taking the limit of $n$ as $n \rightarrow 0$, which corresponds to the small openeconomy assumption, the real exchange rate can be written as Equation (20).

Note 5. If we denote the total nominal money supply of currency $F$ as $M_{F, t}^{*_{s}}$, then $M_{F, t}^{*_{s}}=n M_{F, t}^{s, H}+(1-n) M_{F, t}^{*_{s, F}}$. Note 6. In a frictionless economy, the financial market is complete, prices are flexible, and money is neutral.

Note 7. For example, $\psi_{q}=0$ means a flexible exchange rate regime in which the central bank is unconcerned about deviations in the real exchange rate from its target. $\psi_{q}>0$ means the managed exchange rate regime in which the central bank responds to movement in the real exchange rate by changing the nominal interest rate. $\psi_{q} \rightarrow \infty$ means a fixed exchange rate regime.

Note 8. Since $E_{t}\left[\Delta q_{t+i}{ }^{g}\right]=(1-a)\left\{\left(\hat{i}_{H, t}-E_{t}\left[\pi_{H, t+1}\right]\right)-\hat{r}_{t}^{n}\right\}$, a rise in $\hat{i}_{H, t}$ leads to the appreciation of $q_{t}^{g}$.

Note 9 . We use the current account as the related series.

Note 10. This setting is said to be typical of a small open economy.

Note 11. This is consistent with an average period of one year between price adjustments.

Note 12. For example, the estimated value is 0.07 for inflation-targeting countries and 0.13 for non-inflationtargeting countries in Aizenman et al. (2011).

\section{Copyrights}

Copyright for this article is retained by the author(s), with first publication rights granted to the journal.

This is an open-access article distributed under the terms and conditions of the Creative Commons Attribution license (http://creativecommons.org/licenses/by/4.0/). 